Article

\title{
Investigation of Building Materials Belonging to the Ruins of the Tsogt Palace in Mongolia
}

\author{
Alessandro Sardella ${ }^{1,2, * \mathbb{D}}$, Sonia Canevarolo ${ }^{2}$, Elena Marrocchino ${ }^{3} \mathbb{D}$, Francesca Tittarelli ${ }^{4}$ \\ and Alessandra Bonazza 1 (D) \\ 1 National Research Council of Italy, Institute of Atmospheric Sciences and Climate, 40129 Bologna, Italy; \\ a.bonazza@isac.cnr.it \\ 2 Department of Physics and Earth Sciences, University of Ferrara, 44121 Ferrara, Italy; \\ sonia.canevarolo@unife.it \\ 3 Department of Chemistry, Pharmaceutical and Agricultural Sciences, University of Ferrara, \\ 44121 Ferrara, Italy; mrrlne@unife.it \\ 4 INSTM Research Unit, Department of Materials, Environmental Sciences and Urban Planning (SIMAU), \\ Università Politecnica delle Marche, 60131 Ancona, Italy; f.tittarelli@staff.univpm.it \\ * Correspondence: a.sardella@isac.cnr.it
}

check for updates

Citation: Sardella, A.; Canevarolo, S.; Marrocchino, E.; Tittarelli, F.; Bonazza, A. Investigation of Building Materials Belonging to the Ruins of the Tsogt Palace in Mongolia. Heritage 2021, 4 , 2494-2514. https://doi.org/10.3390/ heritage 4030141

Academic Editor: Nicola Masini

Received: 29 July 2021

Accepted: 15 September 2021

Published: 17 September 2021

Publisher's Note: MDPI stays neutral with regard to jurisdictional claims in published maps and institutional affiliations.

Copyright: (c) 2021 by the authors. Licensee MDPI, Basel, Switzerland. This article is an open access article distributed under the terms and conditions of the Creative Commons Attribution (CC BY) license (https:// creativecommons.org/licenses/by/ $4.0 /)$.

\begin{abstract}
This work focuses on the characterisation of the heritage building materials (plasters, mortars, bricks and glazed tiles) of the Tsogt Palace's ruins located in the Bulgan Province of Mongolia. In addition, contribution is also given to a preliminary evaluation of their state of conservation in consideration of the climate conditions to which the site is exposed. To accomplish the objectives, information on the climate and historical context have been acquired. A set of analytical methodologies has been applied on the seventeen samples collected: Polarized Light (PLM) and Scanning Electron Microscopy coupled with Energy Dispersive X-Ray Spectroscopy (SEM-EDX), X-Ray Diffraction (XRPD), Raman Spectroscopy and Ion Chromatography (IC). The data obtained allowed us to achieve a mineralogical and petrographic characterisation of the samples, underlining the nature of the binder in mortars and plasters, the type of clay used as raw material for bricks and tile, their hypothetical firing temperature and the aggregate composition. Moreover, it was also possible to identify the colouring coating typology in tiles and their process of production. Regarding the state of conservation, the principal deterioration phenomena affecting the site due to environmental impact can be also hypothesised, even though major studies are necessary for an exhaustive assessment.
\end{abstract}

Keywords: degradation; environmental impact; historical building; materials characterisation; production technology

\section{Introduction}

Historical buildings and archaeological sites are a precious source of knowledge of the history and identity of a society and its interaction with the surrounding environment. Several studies have been conducted on the characterisation of ancient construction materials from all over the world, mainly stones and artificial ones like plasters, mortars and bricks as well as the study of their weathering over time [1]. Regarding the deterioration phenomena, every monument outdoor exposed interacts with the surrounding environment and consequently undergoes physical, chemical and/or biological alterations which may be more or less intense depending also on intrinsic features, such as the composition, texture and structure of the constituent materials [2]. Several physical and chemical changes take place in ancient buildings which can result in flaking, powdering, shedding, and cracking [3]. Moreover, in an urban environment, the deterioration is caused by the synergic effect of climate parameters and pollution (mainly induced by transport, heating system and industry) with the increasing pressure of the imposed damage. In the last decades, a high number of 
research studies centred on the mechanisms by which anthropogenic pollution induces damage to cultural heritage (soiling, crystallisation of soluble and insoluble salts, formation of black crust and corrosion caused by acid pollutants) indicating the ever-increasing interest in this issue alongside the effect of climate change [4-8]. Awareness of the potential risks induced by climate change in the conservation of cultural heritage has led to greater attention, especially in Europe, on the present and long-term consequences of its impact on materials through the development of future scenarios of biomass accumulation, thermal stress, and surface recession of stones. Recently particular attention has been given to the risk assessment of cultural heritage exposed to extreme climate events, like heavy rain and prolonged drought periods in Central Europe [9-13]. By contrast, sporadic are the evaluations of impacts of climate change on monuments and archaeological sites outside Europe, above all in Asia and particularly in Mongolia. In addition, in these regions, the mineralogical and petrographical characterisation of building materials in heritage sites is far from being considered a necessary step to be planned and implemented for the assessment of the damage imposed by changes in climate.

This paper reports on the material characterisation and damage evaluation of the Tsogt Palace's ruins located in a remote area in northern Mongolia. Despite several archaeological investigations that have been conducted in Mongolia [14-16], there is an almost total absence of scientific and specialised studies dealing with the characterisation of the historical construction materials and damage assessment. It is also important to consider the nomadic pastoral society that has been always present in this country since the past and the considerable changes over time of the settlement and residence types that, in relation to the inaccessibility of the literature for most of the 20th century (and still present), leads to a difficulty in comparison with other sites in the region [17]. Therefore, the research conducted and herein illustrated represents a starting point for the investigation of Mongolian archaeological sites to carry out an exhaustive characterisation of the building materials (plasters, bedding mortars, bricks and tiles) and to contribute to a first evaluation of the state of conservation due to the environmental impact.

\subsection{Historical Background}

Tsogt Palace' ruins (Figure 1), called by Mongols Tsogtyn Tsagaan baishin (literally White House of Tsogt), are located on the west banks of the Tuul River in Bulgan Province (Northern Mongolia) [18]. It was built in 1601-1617 by the Khalkh prince Tsogt Taij (1580-1637), well known for his resistance to Manchu expansion fighting for Mongolian independence. The house was built on an old building basement with a shape similar to a temple, it was made of stone and bricks, and was covered with coloured Chinese-style roof tiles. The walls measure $36.27 \mathrm{~m}$ on the south-west side, $63.40 \mathrm{~m}$ on the south-east, 33.22 $\mathrm{m}$ on the north-east and $61.87 \mathrm{~m}$ on the north-west. Adjoining buildings' ruins suggest that there is not only one house, information confirmed by the stone stele erected near the palace, which tells us that between 1601 and 1617 there were six monastery buildings also erected in the vicinity [19-21]. 


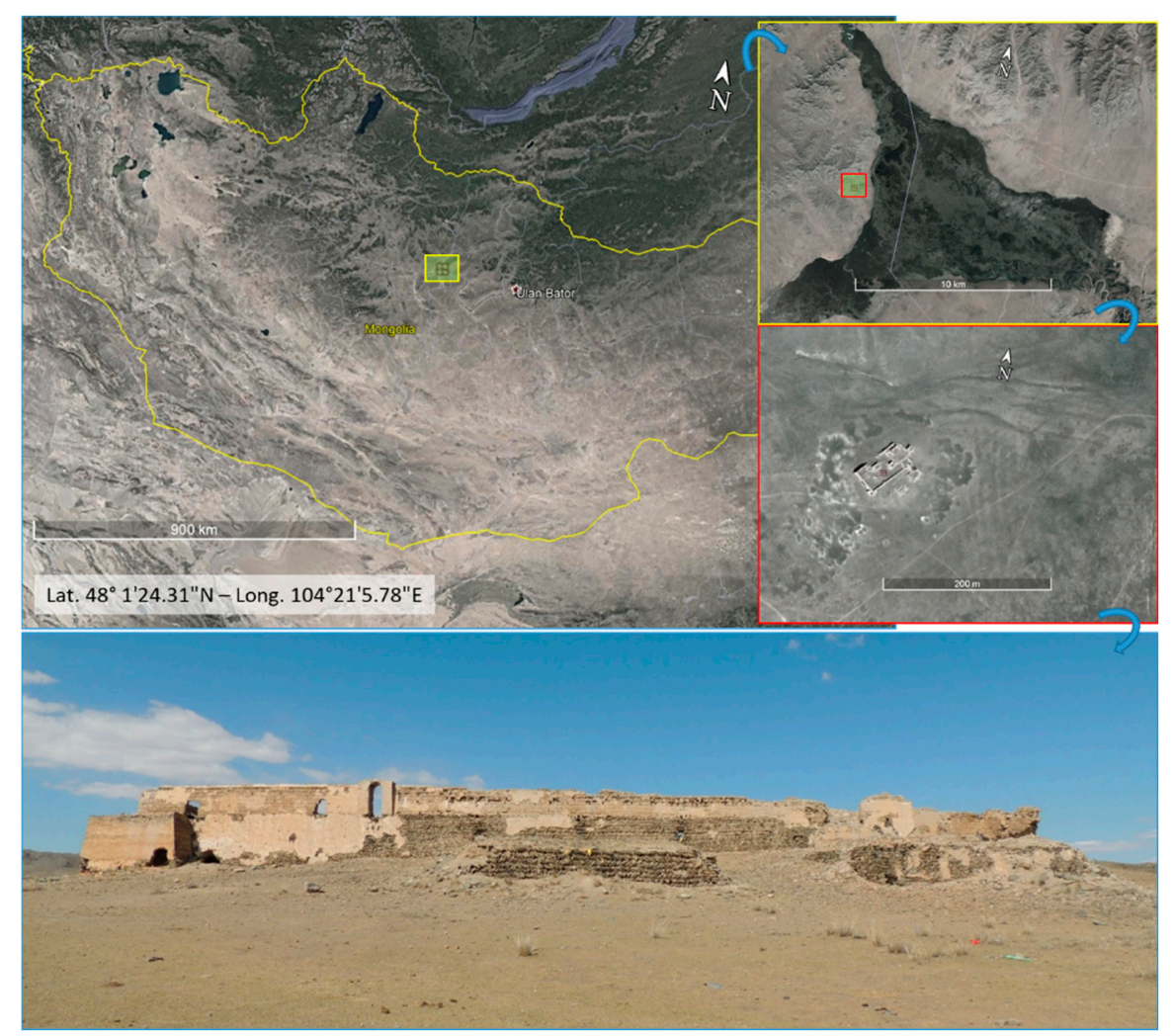

Figure 1. Ensemble of satellite photos (by Google Earth) showing the geographical position of the site including an overviewing photo of the ruins taken during the sampling campaign in 2017 (photo from south-east to north-west).

Archaeological studies have been conducted on the ruins: the palace was firstly examined by the Russian scholar D. A. Klements in 1889; in 1933-1934, Soviet archaeologist D. D. Bukinich investigated the area and its report is stored in the archive of the Institute of History at the Mongolian Academy of Sciences [16,21]. Other surveys on the building were conducted by Mongolian researchers, including Sampildondov Chuluun, a professor of the Institute of History and Archaeology at the Mongolian Academy of Sciences (MAS), who led the research program on the urban development of the Early Modern Period [19]. Since 2013, a national team of the Institute of History and Archaeology (now Institute of Archaeology) established a project entitled "A Seventeenth-Century City", led by Chuluun, which in 2018 affected the ruins of the White House; excavations were conducted within a room on the north-east side of the wall and religious artefacts (clay statues of gods, legendary animals, fish, floral decorations, jade and iron ornaments) were discovered supporting the idea of its use as a monastery for Buddhist activities [22].

Nowadays, the poorly preserved walls of the house were carved with numerous modern inscriptions that were written by visitors, and from 2006 protection zones were set up around the stone stele and building remains of the White House [16,20].

\subsection{Climatic Setting}

Mongolia is a landlocked state situated in north-central Asia that can be subdivided into three major topographic areas spanning mountain chains on the northern and western zones, the basin zones between and around them, and the plateau belt on the southern and eastern zones. According to the large size of the country and topographic diversity, Mongolia's climate is characterised by a great fluctuation in both temperature and precipitation: in the northern regions annual average temperature is around $-22{ }^{\circ} \mathrm{C}$ and $17{ }^{\circ} \mathrm{C}$, with $300-500 \mathrm{~mm}$ of annual precipitation; in central steppes and the south, temperature ranges from $-15^{\circ} \mathrm{C}$ to $21^{\circ} \mathrm{C}$ and precipitation is about $150-250 \mathrm{~mm}$ annually in the steppe zones, 
while the Gobi Desert has only 50-100 mm [23]. Following the most frequently used climate classification map, the Köppen-Geiger classification, Bulgan Province experiences a cool continental climate/subarctic climate (Dwc) with long, dry, very cold winters and short, warm summers [24]. The average winter temperature falls between $-19^{\circ} \mathrm{C}$ and $-24^{\circ} \mathrm{C}$ while in summer it rises between $+14^{\circ} \mathrm{C}$ and $+19{ }^{\circ} \mathrm{C}$. The average rainfall is estimated between $220 \mathrm{~mm}$ and $420 \mathrm{~mm}$ [16]. Regarding climate change, the specific geographical and climatic conditions, the dependence on coal-based energy and the growing urban population contribute to increasing Mongolia's vulnerability to extreme weather impacts. Climate projections include a $2-3{ }^{\circ} \mathrm{C}$ increase in average annual temperature, melting of the permafrost throughout the 21st century, more variable precipitation with a decrease in summer and an increase in winter, more frequent extreme events like droughts, flash floods, heavy precipitation, windstorm, snowstorm and $d z u d s$ (Phenomenon mainly caused by summer drought followed by sudden spurts of heavy snowfall, long-lasting or frequent snowfall, extremely low temperature or drifting windstorms.) [23]. Regarding air pollution, it has become one of the most alarming issues in Mongolia due to various factors. The major pollution contributors include the use of fossil fuels intensified during winter for household heating, vehicular emissions, and coal-based technologies for electricity generation. The capital city Ulaanbaatar accommodates 46 percent of Mongolia's population and it emerges as the most polluted area in the country. In this city, $\mathrm{SO}_{2}, \mathrm{NO}_{2}$, particulate matter $\left(\mathrm{PM}_{10}\right.$ and $\left.\mathrm{PM}_{2.5}\right), \mathrm{O}_{3}$ and $\mathrm{CO}$ emission values all overshoot the Mongolian air quality standards [25].

Tsogt Palace' ruins, located at around $190 \mathrm{~km}$ from Ulaanbaatar, are in a remote zone of northern Mongolia which is assumed to be unaffected by pollution. On the other hand, being an area with a climate characterised by significant fluctuations in temperature and precipitation, decohesion and fracturing due to freeze-thaw cycling, thermoclastism linked to heating and cooling of the material surface, erosion and surface recession may be harmful to the building materials.

\section{Materials and Methods}

\subsection{Material Sampling}

A sampling campaign was conducted in April 2017 where 17 specimens were collected representative of the different types of building materials present (brick, mortar, plaster and tile) and their state of conservation (Tables 1 and 2). Samples were taken from the remaining portions of brick masonry (with bricks and bedding mortars), partially coated with plasters. Moreover, specimens of the roof tiles were collected from the remains present on the ground within the perimeter of the walls. As indicated in Section 1.1, the ruins are a protected archaeological site located in a remote area that was abandoned for many years. During the survey, it was evident the structural unstable conditions of the site with the roof of the original building no longer present and most of the perimeter brick walls at risk of collapse. Original plastering mortars were almost totally absent and bedding mortars frequently eroded and decohesionated (Figure 2). Visible biological colonisation was also found mainly on the remains of the original plasters and bricks exposed to NW and NE. 
Table 1. List of the samples with their collection position and main characteristics by visual observation (material abbreviation: P-plaster, M-mortar, B-brick, T-tile, R-residual material).

\begin{tabular}{|c|c|c|c|c|c|c|}
\hline \multirow[t]{2}{*}{$\begin{array}{l}\text { Sample } \\
\text { Name }\end{array}$} & \multirow[t]{2}{*}{$\begin{array}{l}\text { Material } \\
\text { Sampled }\end{array}$} & \multicolumn{2}{|c|}{$\begin{array}{c}\text { Sampling High } \\
\text { (cm from the Ground Floor) }\end{array}$} & \multicolumn{2}{|c|}{$\begin{array}{c}\text { Sampling Depth } \\
\text { (cm from the External Surface) }\end{array}$} & \multirow[t]{2}{*}{ Brief Description } \\
\hline & & from & to & from & to & \\
\hline TPR1P & $\mathrm{P}$ & 45 & 50 & 0 & 1 & White plaster \\
\hline TPR2M & $\mathrm{M}$ & 40 & 45 & 0 & 1 & Brown bedding mortar \\
\hline TPR3B & $\mathrm{B}$ & 150 & 160 & 0 & 2 & Brown-yellowish brick \\
\hline TPR4B & B & 105 & 110 & 0 & 2 & Green-grey brick \\
\hline TPR5P & $\mathrm{P}$ & 130 & 135 & 0 & 2 & White plaster \\
\hline TPR6M & M & 125 & 130 & 0 & 2 & $\begin{array}{l}\text { Light brown bedding } \\
\text { mortar }\end{array}$ \\
\hline TPR7B & B & 125 & 128 & 0 & 2 & Grey brick \\
\hline TPR8B & B & 130 & 135 & 0 & 2 & Red brick \\
\hline TPR9AT & $\mathrm{T}$ & / & / & / & / & Light yellow glazed tile \\
\hline TPR9BT & $\mathrm{T}$ & / & / & / & / & Dark yellow glazed tile \\
\hline TPR10T & $\mathrm{T}$ & / & / & / & / & Dark green glazed tile \\
\hline TPR11T & $\mathrm{T}$ & / & / & / & / & Green glazed tile \\
\hline TPR12T & $\mathrm{T}$ & / & / & / & / & Green-light blue glazed tile \\
\hline TPR13T & $\mathrm{T}$ & / & / & / & / & Red glazed tile \\
\hline TPR14T & $\mathrm{T}$ & / & / & / & / & Grey-light blue glazed tile \\
\hline TPR15T & $\mathrm{T}$ & / & / & / & / & Red-brownish glazed tile \\
\hline TPR16R & $\mathrm{R}$ & / & / & / & / & Whitish residual material \\
\hline
\end{tabular}

Table 2. List, photo and location of each sampling point with an indication of the damage type (according to ICOMOS standardised glossary) and related degree of the severity of damage (+++: severe, ++ : moderate, + : mild).

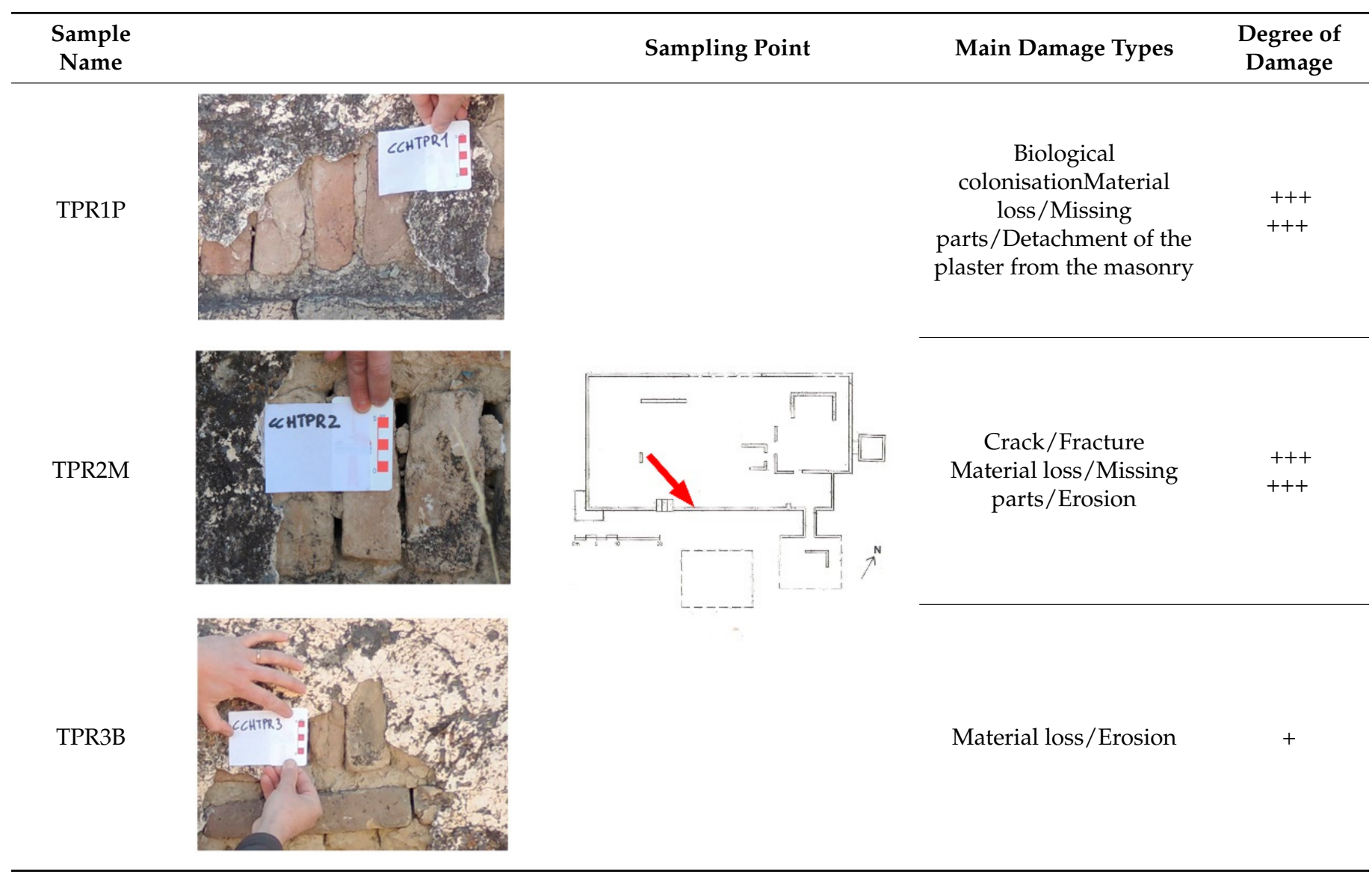


Table 2. Cont

\begin{tabular}{|c|c|c|c|}
\hline $\begin{array}{l}\text { Sample } \\
\text { Name }\end{array}$ & Sampling Point & Main Damage Types & $\begin{array}{c}\text { Degree of } \\
\text { Damage }\end{array}$ \\
\hline TPR4B & & $\begin{array}{c}\text { Crack/Fracture } \\
\text { Material loss/Missing } \\
\text { parts } \\
\text { Biological colonisation }\end{array}$ & $\begin{array}{l}++ \\
++ \\
++\end{array}$ \\
\hline TPR5P & & $\begin{array}{l}\text { Material loss/Missing } \\
\text { parts/Detachment of the } \\
\text { plaster from the masonry } \\
\text { Material loss/Microkarst }\end{array}$ & $\begin{array}{l}+++ \\
++\end{array}$ \\
\hline TPR6M & & $\begin{array}{l}\text { Material loss/Microkarst } \\
\text { Material loss/Erosion }\end{array}$ & $\begin{array}{l}++ \\
++\end{array}$ \\
\hline TPR7B & & $\begin{array}{c}\text { Discolouration \& } \\
\text { Deposits/Colouration }\end{array}$ & ++ \\
\hline TPR8B & & Biological colonisation & ++ \\
\hline
\end{tabular}


Table 2. Cont

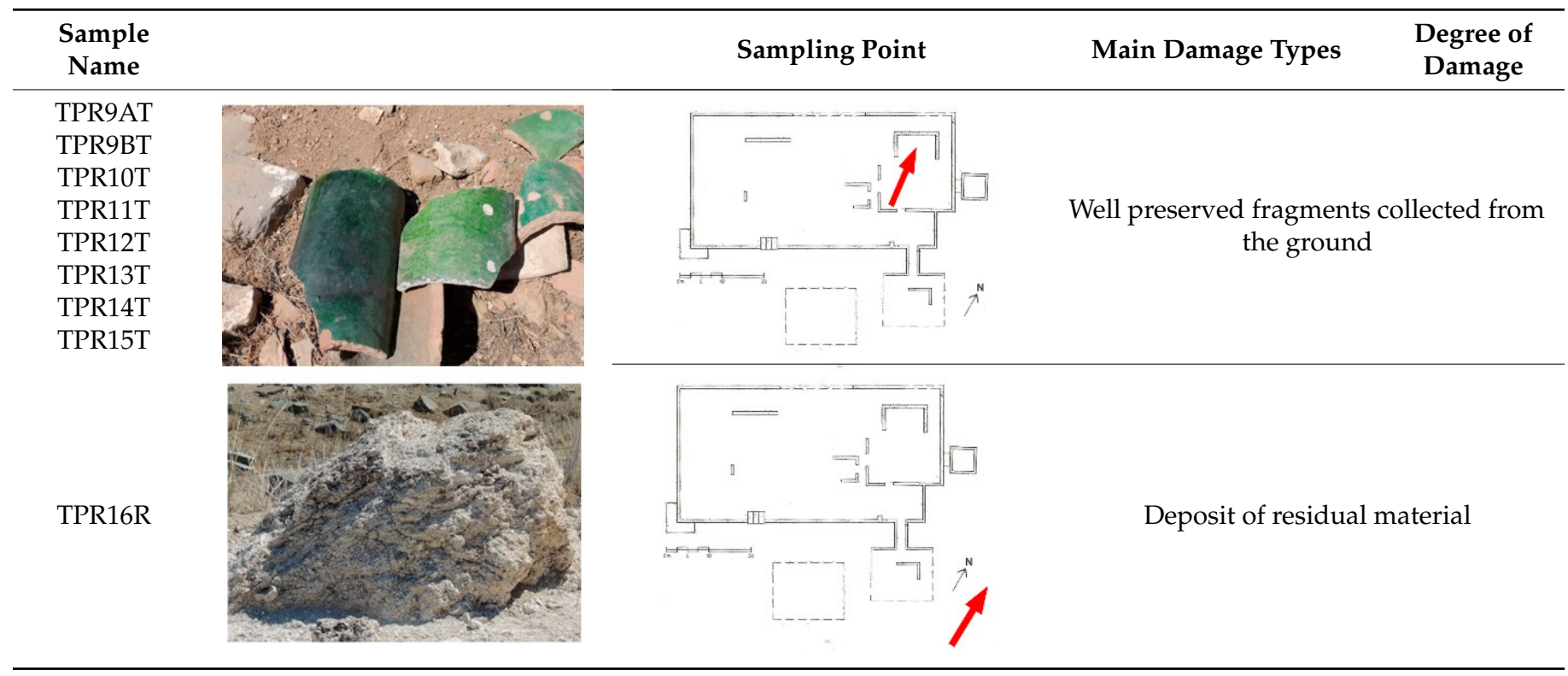

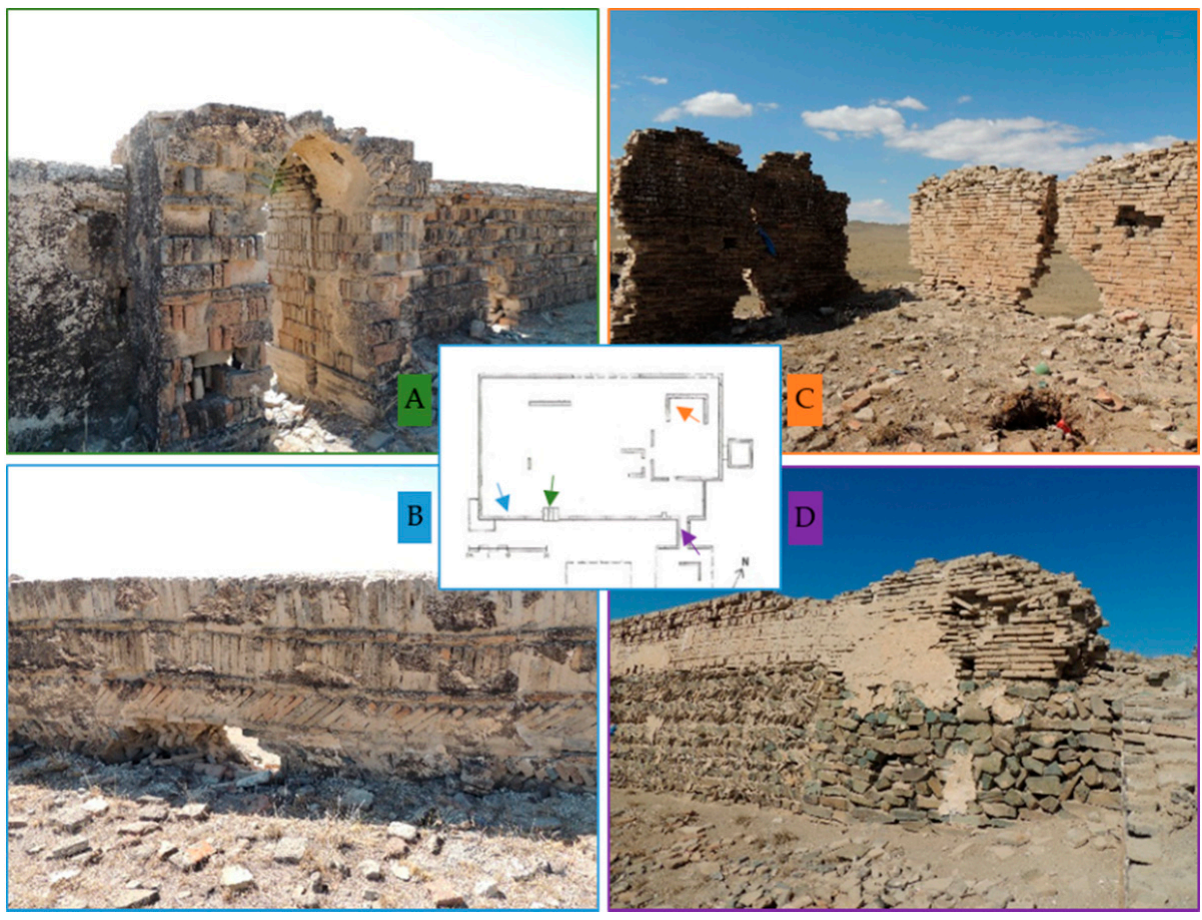

Figure 2. Photos of the palace ruins taken during the sampling campaign in 2017 showing the remains of the perimetral walls and their building technique. Coloured arrows in the central map represent the photo shooting points: (A) one of the doors at the South wall, (B) particular of the building technique of the bricks masonry at the South wall, (C) remains of interior brick masonries at the north-east side of the ruins and (D) remains of the masonries built with stone and bricks and partially covered by plaster located at south-east gate of the palace.

These conditions made particularly unsafe the sampling of material from almost all the areas of the archaeological site and therefore represented a limit for the samples collection. The sampling was planned and performed in agreement with the requirements given by the National Centre for Cultural Heritage of Mongolia: low invasiveness and minimum number and amount of material necessary for preliminary characterisation of the typologies of building materials and evaluation of their state of conservation. Samples 
of plaster (TPR1P, TPR5P), mortar (TPR2M, TPR6M) and brick (TPR3B, TPR4B) were taken from different masonries, while coloured (yellow, green, red, light blue) glaze tile samples (TPR9AT-TPR15T) were picked up from the ground within the building's walls (Figure 3). In addition, a sample of residual material from a pile close to the ruins was taken to verify its potential use as a binder for plaster and mortar (TPR16R). Detailed information on the collected samples with sampling position and indication of the damage type according to the ICOMOS standardised glossary [26] is provided in Tables 1 and 2.

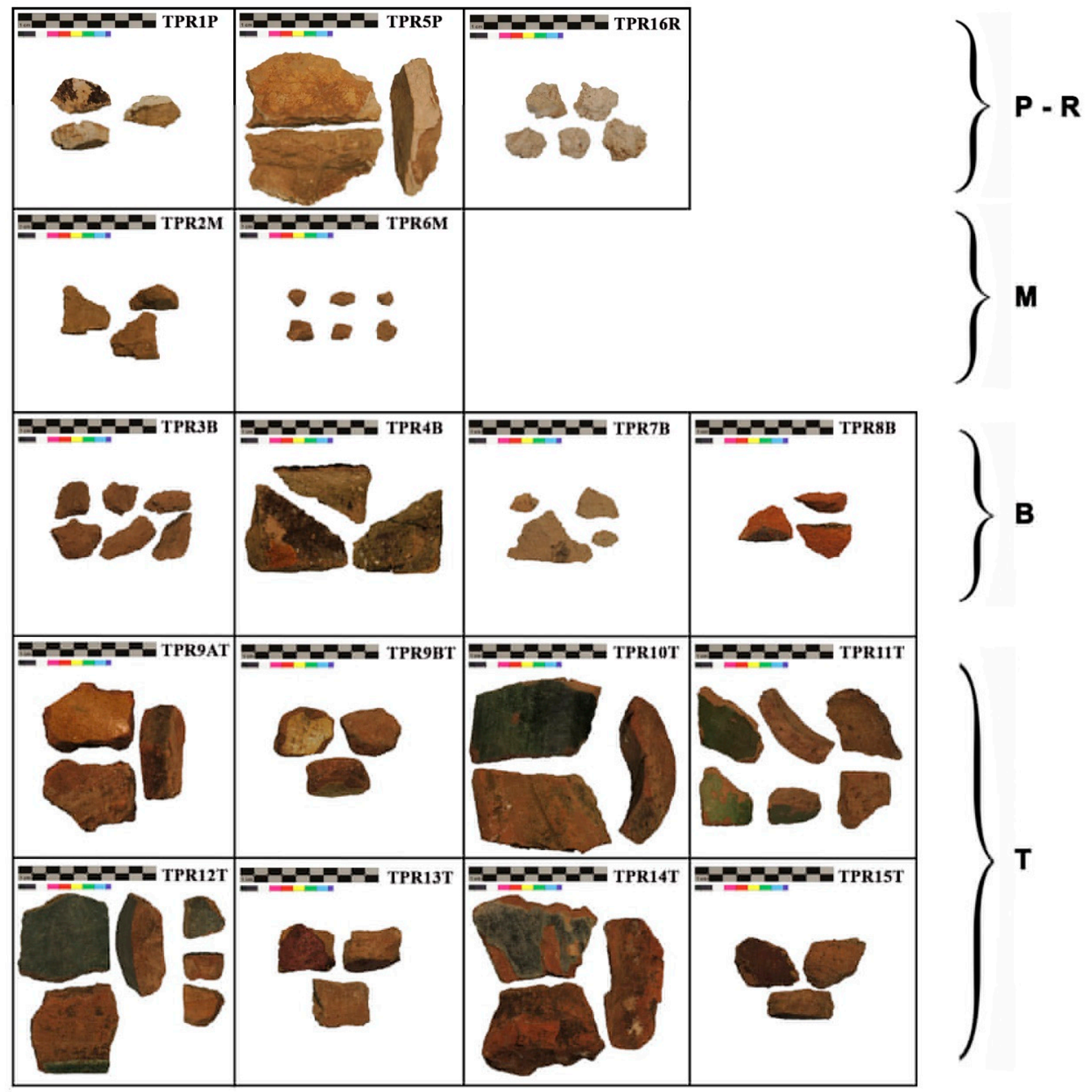

Figure 3. Macroscopic photos of samples subdivided by material ( $\mathrm{P}$ - plaster, $\mathrm{R}$-residual material, $\mathrm{M}$-mortar, $\mathrm{B}$ - brick, T-tile).

\subsection{Analyses}

On the collected specimens, a series of laboratory investigations were carried out.

Firstly, the samples underwent macroscopical observation to set up the most appropriate analyses to perform in relation also to the type of sample and available amount of material for each specimen. 
Petrographic characterisation has been conducted by Polarized Light Microscopy (PLM) observation on a thin section with an Olympus BX 51 microscope. Acquisition, storage, analyses and image processing with interactive measurement function has been also possible by the use of a scanner and the MICROMAX software "Primoplus_32" vers. 8.11.02 bundled in the microscope. Thin sections were prepared by impregnating the samples with a resin and then cutting and polishing the samples to obtain thin sections of 25-30 $\mu \mathrm{m}$ thickness. The petrographic analysis has been focused on the determination of the compositional characteristics and texture of samples (e.g., mineralogy, size distribution and shape of grains and pores). In addition, a semi-quantitative estimation of the amount of each aggregate component and the porosity has been done by the use of comparison charts for visual percentage estimation published by Terry and Chilingar [27].

To implement the knowledge on the mineralogical phases present, X-Ray Powder Diffraction (XRPD) has been applied. The samples were prepared by preliminary partial separation of the coarse aggregate fraction by soft mechanical grinding and manual removal by tweezers, to have samples with higher representativeness of the mineralogical composition of the binder and the finer part of the aggregate not easily detectable by PLM. In addition, the glaze layer was removed from the tile samples. The instrument used for the XRPD analyses is a Philips PW 1710 equipped with a copper anode tube and a nickel filter; the conditions used consist of a diffraction interval of $2 \varnothing$, between $5.010^{\circ}$ and $69.990^{\circ}$, a step size of $0.020^{\circ}$ and a time per step of $2.000 \mathrm{~s}$ at $40 \mathrm{kV}$ voltage and $30 \mathrm{~mA}$ current intensity.

The morphological characteristics and the elemental analyses of glazed tiles and the residual material used as binders in mortars and plasters have been obtained through Scanning Electron Microscopy coupled with Energy Dispersive X-Ray Spectroscopy (SEMEDX). The analyses have been performed on untreated fragments of the sample with a Zeiss EVO 40 Scanning Electron Microscope with LaB6 source, equipped with an AZtec Oxford EDS microanalysis system.

Raman spectroscopy has been applied on untreated fragments of the coloured tile samples to investigate the glaze composition, particularly the colouring agents used. A LabRam HR800 micro-Raman instrument from Horiba Scientific equipped with an aircooled CCD detector at $-70^{\circ} \mathrm{C}$, an Olympus BXFM microscope, a 600 groove $/ \mathrm{mm}$ grating and a $50 \times$ objective were used to collect the Raman scattering signals. The excitation source was a He-Ne laser (632.8 nm line) with a maximum laser power of $20 \mathrm{~mW}$ and the spectrometer was calibrated with silicon at $520 \mathrm{~cm}^{-1}$.

To evaluate the possible presence of soluble salts, Ion Chromatography analysis (IC) has been performed on powdered mortars and plasters; a DIONEX ICS 900 has been used. Anions analysis: Column S23 Pre-column G23; cation analysis: Column CS12 Pre-column CG12. The samples have been finely ground to obtain a talc consistency ( $90 \mu \mathrm{m}$ sieve pass). About $25 \mathrm{mg}$ of powder were placed in a $25 \mathrm{cc}$ graduated flask and made up to the volume with bi-deionised water. To favour dissolution, the flasks are placed in an ultrasonic bath for $22 \mathrm{~min}$ at $40^{\circ} \mathrm{C}$. The solution obtained is analysed with the chromatograph. The procedure allows to measure the concentration (ppm) of (i) anions: fluoride, acetate, formate, chloride, nitrite, bromide, nitrate, phosphate, sulphate, oxalate and (ii) cations: lithium, sodium, ammonium, potassium, magnesium, calcium.

A brief description of each sample and the analyses executed are summarised in Table 3. 
Table 3. List of the analyses performed on each sample.

\begin{tabular}{|c|c|c|c|c|c|c|}
\hline \multirow{2}{*}{ Sample } & \multirow{2}{*}{ Material } & \multicolumn{5}{|c|}{ Analyses } \\
\hline & & PLM & XRPD & IC & SEM-EDS & Raman \\
\hline TPR1P & \multirow{2}{*}{ Plasters } & $\checkmark$ & $\checkmark$ & $\checkmark$ & & \\
\hline TPR5P & & $\checkmark$ & $\checkmark$ & $\checkmark$ & & \\
\hline TPR2M & \multirow{2}{*}{ Mortars } & $\checkmark$ & $\checkmark$ & $\checkmark$ & & \\
\hline TPR6M & & $\checkmark$ & $\checkmark$ & $\checkmark$ & & \\
\hline TPR3B & \multirow{4}{*}{ Bricks } & $\checkmark$ & $\checkmark$ & & & \\
\hline TPR4B & & $\checkmark$ & $\checkmark$ & & & \\
\hline TPR7B & & $\checkmark$ & $\checkmark$ & & & \\
\hline TPR8B & & $\checkmark$ & $\checkmark$ & & & \\
\hline TPR9AT & \multirow{8}{*}{ Tiles } & $\checkmark$ & $\checkmark$ & & $\checkmark$ & $\checkmark$ \\
\hline TPR9BT & & $\checkmark$ & $\checkmark$ & & $\checkmark$ & $\checkmark$ \\
\hline TPR10T & & $\checkmark$ & $\checkmark$ & & $\checkmark$ & $\checkmark$ \\
\hline TPR11T & & $\checkmark$ & $\checkmark$ & & $\checkmark$ & $\checkmark$ \\
\hline TPR12T & & $\checkmark$ & $\checkmark$ & & & $\checkmark$ \\
\hline TPR13T & & $\checkmark$ & $\checkmark$ & & $\checkmark$ & $\checkmark$ \\
\hline TPR14T & & $\checkmark$ & $\checkmark$ & & $\checkmark$ & $\checkmark$ \\
\hline TPR15T & & $\checkmark$ & $\checkmark$ & & $\checkmark$ & $\checkmark$ \\
\hline TPR16R & $\begin{array}{l}\text { Residual } \\
\text { material }\end{array}$ & $\checkmark$ & $\checkmark$ & $\checkmark$ & $\checkmark$ & \\
\hline
\end{tabular}

\section{Results and Discussion}

\subsection{Materials Characterisation}

\subsubsection{Plasters and Mortars}

The petrographic observations of plasters and mortars, performed by PLM, reveal a carbonatic binder with a micritic texture containing rounded nodules of lime $(\mathrm{CaO})$ (Figure 4A), which may indicate that the lime was slaked with a minimum amount of water to convert it into calcium hydroxide $\mathrm{Ca}(\mathrm{OH})_{2}$ [28]. The aggregate presents different sizes between plaster and mortar samples. In fact, the aggregate in plasters mainly has a fine sand grainsize, while the mortars are characterised by a medium to fine sand grainsize. 
(A)

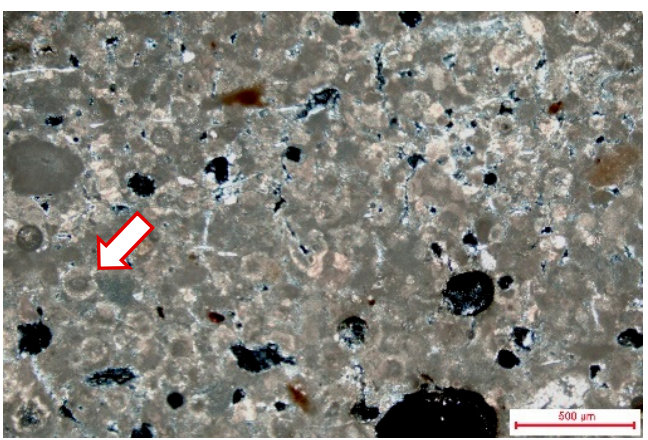

(C)

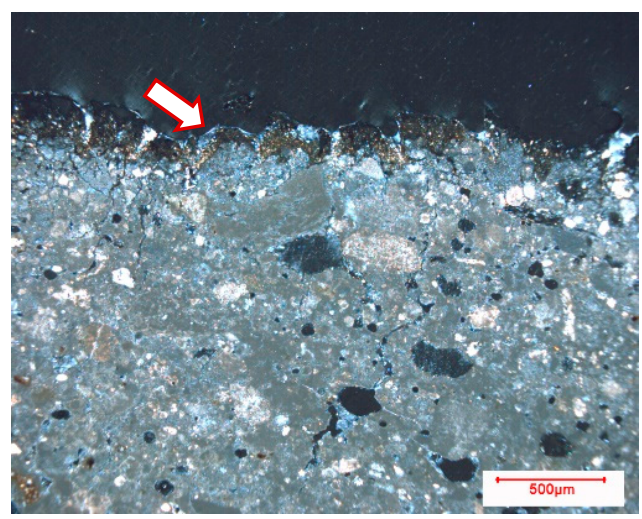

(E)

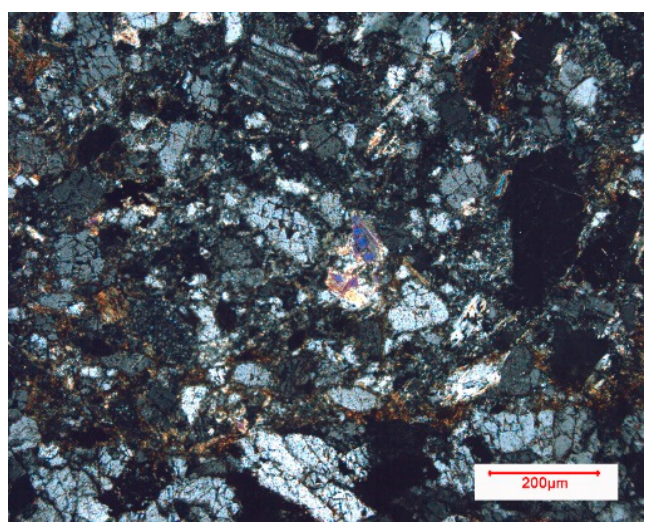

(B)

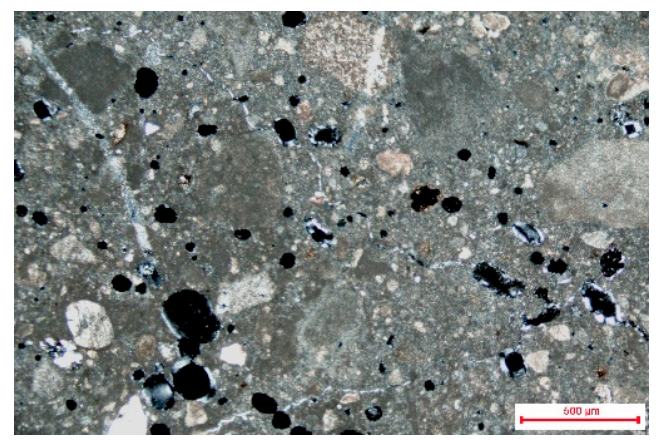

(D)

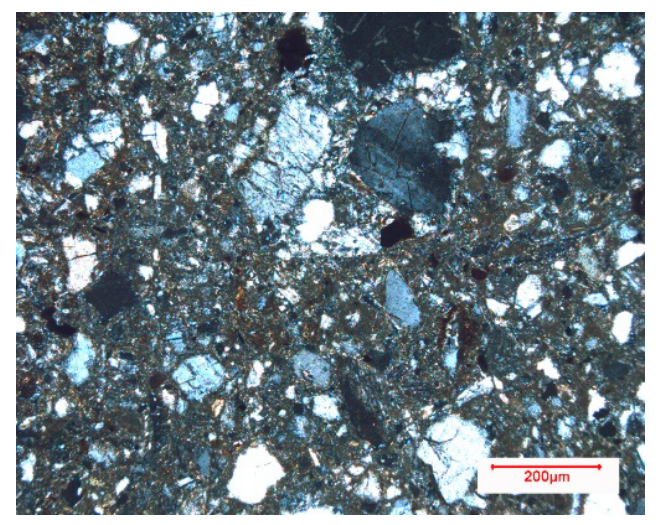

(F)

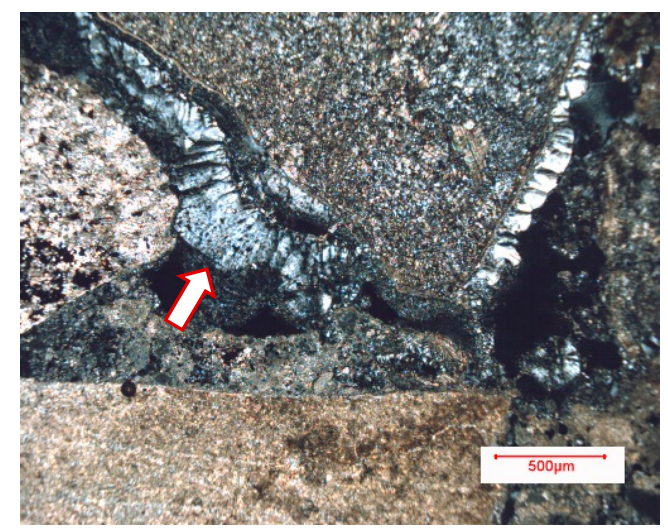

Figure 4. Photomicrographies (xpl—crossed polarised light) of samples of mortar, plaster and residual material observed by PLM: (A) TPR1P, showing rounded nodules of lime; (B) TPR5P. Aggregate composition and porosity; (C) TPR1P. Stratigraphy in which a damage layer ascribable to biological deterioration is visible; (D) TPR2M. Aggregate composition and distribution; (E) TPR6M composition, in which felspar (plagioclase) represents the predominant mineralogical phase; (F) residual material TPR16R. Detail of radial fibrous crystallisation.

The plasters (TPR1P, TPR5P) have a low aggregate/binder ratio (20\%), with homogeneously distributed and moderately well-sorted aggregate, characterised by subrounded and subangular shapes. In the aggregate, it is possible to recognise quartz and felspar as the two major mineral fragments (more in TPR5P than TPR1P), with a small amount of femic minerals (predominantly biotite), fragments of micritic calcite and fragments of metamorphic rock, mostly quartzite (Figure 4B). Moreover, TPR1P shows biological deterioration on the outer layer which has also caused decohesion and cracking on the part of the plaster 
in contact with it (Figure 4C). Mortar samples (TPR2M, TPR6M) display medium-high aggregate/binder ratio (40-50\%). The aggregate is homogeneously distributed and moderately well sorted with subrounded and sub-angular shapes (Figure 4D). Petrographic observation reveals that also for mortars quartz and felspar (which results predominantly in TPR6M, Figure 4E) are the two major minerals observed; the other minerals constitute only a small percentage and are composed of femic minerals (biotite) and fragments of metamorphic rock, predominantly made of quartz.

The porosity of plasters and mortars estimated by visual comparison charts from Terry and Chlingar, 1955 [27] varies from low to medium (20-30\%) with rounded/subrounded shape.

TPR16R sample presents a carbonatic composition showing uneven areas with different crystallinity and secondary phase minerals with a radial fibrous crystallisation along veins and pores (Figure $4 \mathrm{~F}$ ) that could be ascribable to the use of a mixture of calcic and magnesian lime $[29,30]$. This material displays shrinkage fissuring and inhomogeneous pores distribution with irregular shapes.

As noticeable in Table 4, in plasters and mortars, the carbonatic composition of the binder has been confirmed by XRD analysis. Plaster samples (TPR1P and TPR5P) display calcite as the main component followed by quartz mainly entirely ascribable to the aggregate. Instead, the two mortar samples (TRP2M and TPR6M) display quartz as the main phase (where it is present as crystals and in rock fragments in the aggregate), feldspar moderately abundant, calcite, quartz, and chlorite in traces. TPR6M also shows the presence of mica (muscovite/illite) and amphibole, probably hornblende. The residual material sample TPR16R displays calcite as the main component, while traces of quartz and hydromagnesite have been also found.

Table 4. XRD analysis results. Legend: Cal = Calcite; Qtz = Quartz; Fsp = Feldspar; Chl = Chlorite; Mic = Mica; Amph = Amphibole, Hmgs = Hydromagnesite; Hem = Hematite ++++++ = dominant; ++++ = abundant; $+++=$ moderately abundant; $++=$ present $;+$ = traces; - = absent.

\begin{tabular}{|c|c|c|c|c|c|c|c|c|c|}
\hline Sample & Material & Cal & Qtz & $F s p$ & Chl & Mic & Amph & Hmgs & Hem \\
\hline TPR1P & \multirow{2}{*}{ Plaster } & +++++ & ++ & - & - & - & - & - & - \\
\hline TPR5P & & +++++ & ++ & - & - & - & - & - & - \\
\hline$T P R 2 M$ & \multirow{2}{*}{ Mortar } & + & +++++ & +++ & $+/-$ & - & - & - & - \\
\hline TPR6M & & ++ & +++++ & $+++/++++$ & + & $+/-$ & $+/-$ & - & - \\
\hline TPR3B & \multirow{4}{*}{ Brick } & + & +++++ & +++ & $+/-$ & - & - & - & - \\
\hline TPR4B & & - & +++++ & ++ & - & - & - & - & + \\
\hline TPR7B & & - & +++++ & ++ & - & - & - & - & - \\
\hline TPR8B & & - & +++++ & ++ & - & - & - & - & - \\
\hline TPR9AT & \multirow{8}{*}{ Tile } & - & +++++ & ++ & - & - & - & - & - \\
\hline TPR9BT & & - & +++++ & $+/++$ & - & - & - & - & - \\
\hline TPR10T & & - & +++++ & $+/++$ & - & - & - & - & - \\
\hline TPR11T & & - & +++++ & $+/++$ & - & $+/-$ & $+/-$ & - & - \\
\hline TPR12T & & - & +++++ & ++ & - & - & - & - & - \\
\hline TPR13T & & - & +++++ & $+/++$ & - & $+/-$ & - & - & - \\
\hline TPR14T & & - & +++++ & $+/++$ & - & - & - & - & - \\
\hline TPR15T & & - & +++++ & ++ & - & - & - & - & - \\
\hline TPR16R & $\begin{array}{c}\text { Residual } \\
\text { material }\end{array}$ & +++++ & + & - & - & - & - & + & - \\
\hline
\end{tabular}

SEM-EDS has been particularly applied for the elemental identification of the secondary phase crystals present in TPR16R (residual material) observed through PLM analy- 
sis, highlighting magnesium, calcium, and silicon as main detected elements (Figure 5A). The radial fibrous crystals are prevalently composed of magnesium which confirms they are hydromagnesite crystals (Figure $5 \mathrm{~B}$ ) formed through the separation of the magnesium phase with respect to the calcite phase [29,30]. Based on the obtained results by PLM, XRD and SEM-EDS, TPR16R results to be a mixture of calcic and magnesian lime. As we did not find evidence of $\mathrm{Mg}$ carbonates (magnesite, dolomite), $\mathrm{Mg}$ hydrated carbonates or $\mathrm{Mg}$ hydroxyl carbonates in the samples of mortars and plaster analysed, we can argue that they are composed of calcic lime and that the residual material has not been likely used for their production. Nevertheless, it should be taken into consideration that the detection and identification of the minerals phase in low concentration $(<5 \%)$ by XRD is difficult, particularly in dealing with complex matrices as mortars, and that peak of hydromagnesite is attenuated when calcite is present, being undetectable at concentrations below $20 \%[31,32]$.

(A)
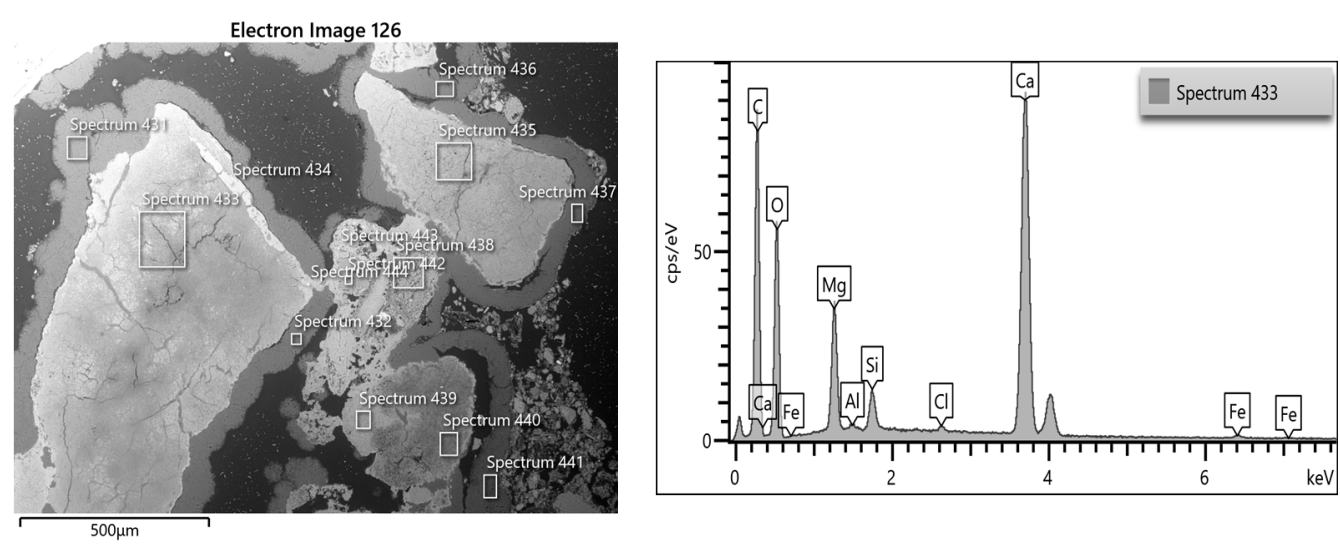

(B)
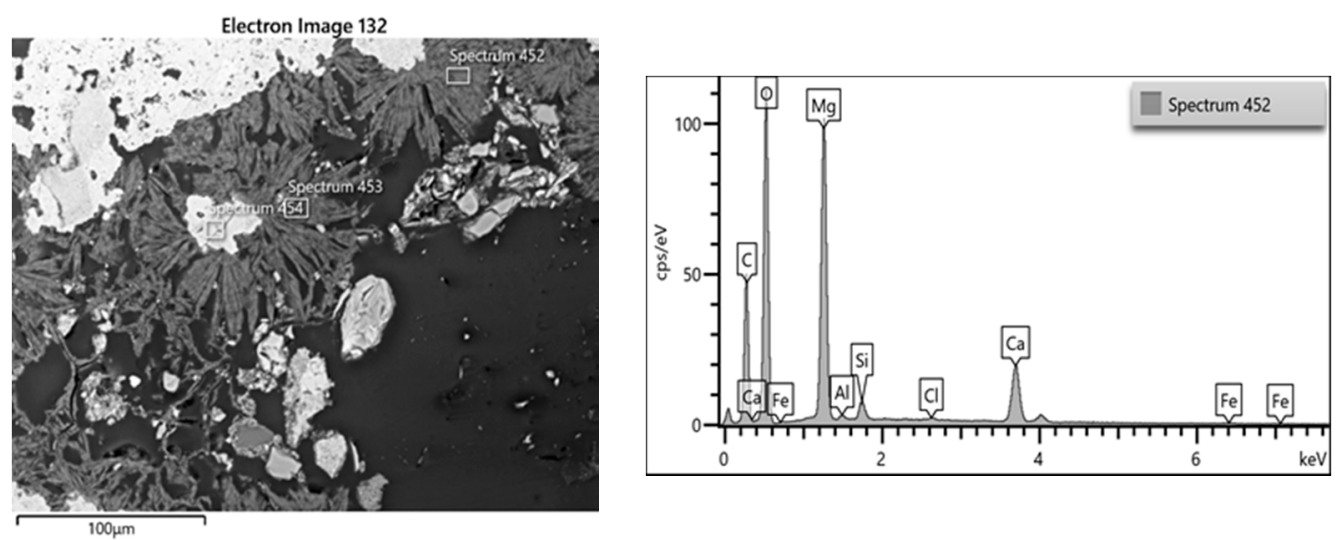

Figure 5. SEM photomicrographies of the residual material sample (TPR16R) and associated EDS spectrum highlighting its overall composition (A) and fibrous radial crystals of hydromagnesite with the presence of magnesium in the relative spectrum $(\mathbf{B})$.

\subsubsection{Bricks}

All the samples display a coloured microcrystalline partially amorphous matrix and medium-high detrital grains content. The matrix/aggregate ratio goes from medium to high and the aggregate varies from moderately well sorted to poorly sorted; the shape varies from subrounded to subangular with different grain sizes. Porosity varies from very low to medium with mainly subrounded pores of different sizes not much homogeneously distributed. 
The four brick samples show a different colouration of the matrix ranging from pinkish (TPR3B), yellowish (TPR4B), to brownish (TPR7B) and bright red (TPR8B). Sample TPR3B has a slightly low matrix/aggregate ratio with respect to the other bricks, with variable aggregate crystal sizes. Feldspar (plagioclase) is the most abundant mineralogical phase (Figure 6A), followed by quartz, and a few fragments of metamorphic rock (quartzite). Sample TPR4B is also characterised by the inclusion of cocciopesto (crushed bricks) and sporadic fragments of carbonate metamorphic stone. The detrital grains are mostly quartz, followed by feldspar; mortar fragments are also present (Figure 6B). In sample TPR7B the matrix is brownish, and large pieces of mortar are visible macroscopically (Figure 6C). TPR8B, with a bright red matrix, has a medium matrix/aggregate ratio. As for the TPR3B sample, feldspars are the major mineralogical phase present, followed by quartz and femic minerals (biotite) (Figure 6D).

(A)

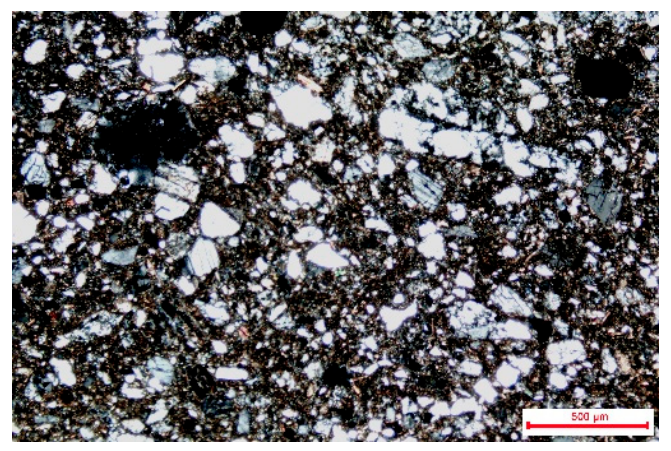

(C)

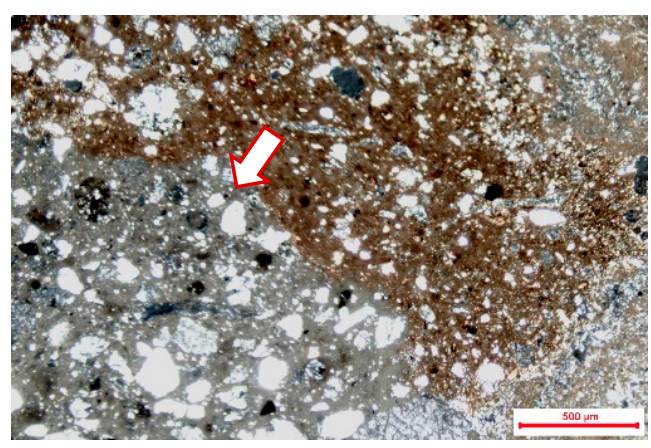

(B)

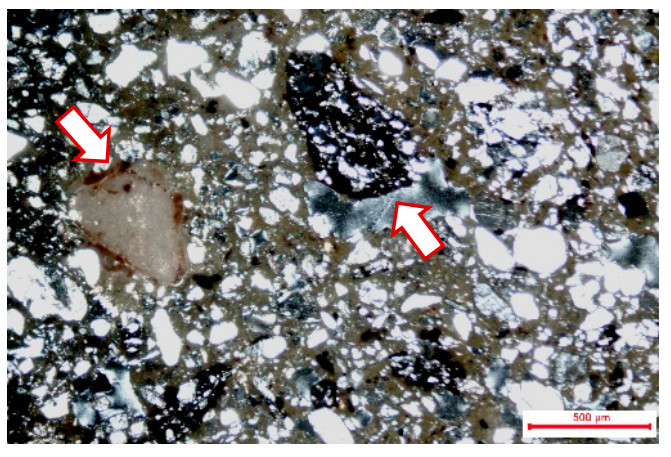

(D)

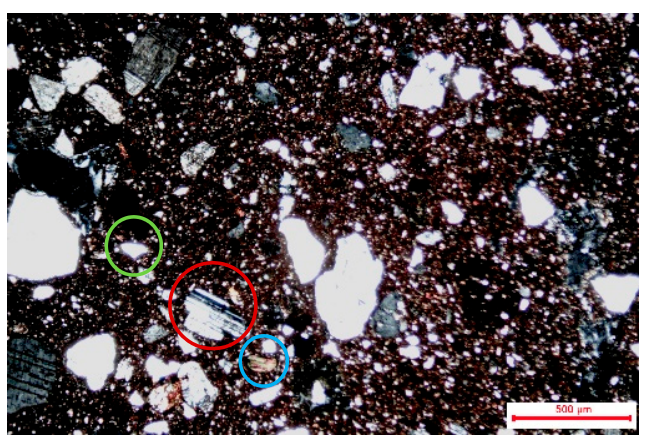

Figure 6. Photomicrographies (xpl) of brick samples observed by PLM: (A) TPR3B. Aggregate composition and distribution; (B) TPR4B. A large piece of an old mortar with reaction border and coccio pesto fragments; (C) TPR7B. Pieces of old mortar (grey area) as an aggregate constituent; (D) TPR8B showing a bright red matrix in which feldspar (red), quartz (green) and biotite (light blue) crystals are visible.

In XRD results (Table 3), bricks display similar composition with quartz as the main component and feldspar (plagioclase and k-feldspars) moderately abundant. Calcite (related to the rare carbonate stone fragments identified in the inclusions by PLM) and traces of chlorite have been detected in TPR3B while traces of hematite have been found in TPR4B.

Based on the detected mineralogical composition and petrographical features by PLM and XRD, an estimation of $900-950^{\circ} \mathrm{C}$ can be argued for the brick samples, except for TPR3B for which a fire temperature ranging from $850{ }^{\circ} \mathrm{C}$ and $900{ }^{\circ} \mathrm{C}$ could be suggested. This is mainly explained by the absence of clay minerals $[33,34]$ supported by the dark colour of the clay matrix [35]. It can be also noticed that the absence of diopside and gehlenite supports the use of non-calcareous clays as raw material [33]. It should be underlined 
that in contrast to Ca-rich clays where high-temperature mineral phases indicate the firing temperature, in Ca-poor clays high temperature induces textural modifications only without major compositional changes [36]. This implies a higher difficulty for the firing temperature estimation.

\subsubsection{Tiles}

All the samples display a coloured microcrystalline partially amorphous matrix and high detrital grains content. The matrix/aggregate ratio goes from medium to high and the aggregate varies from moderately well sorted to poorly sorted; the shape varies from subrounded to subangular with different grain sizes. The tile samples show a fairly homogeneous clay matrix colour (dark red) with a slightly different grain size of the detrital grains.

Quartz (monocrystalline and polycrystalline) is the most abundant mineral in all samples, followed by feldspar (Figure 7A), some micas (biotite, muscovite) and amphiboles (hornblende and a fibrous variety of amphibole, Figure 7B). Metamorphic rock fragments (quartzite) with variable sizes (Figure 7C) are also present like some pieces of cocciopesto, old mortars and over burned lime.

(A)

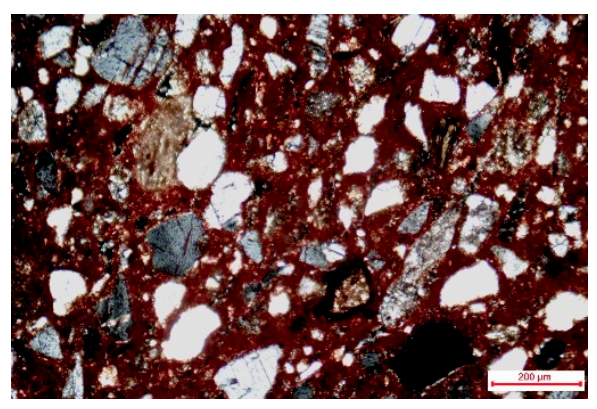

(C)

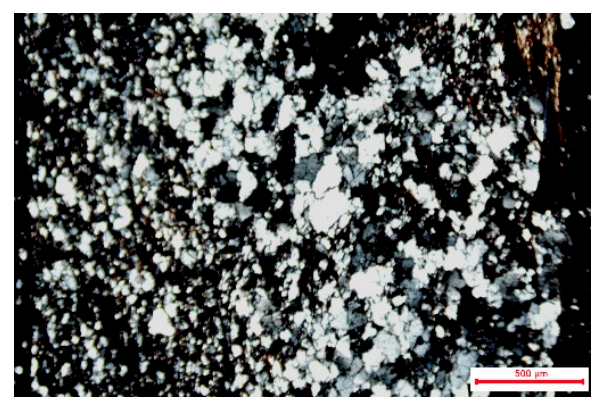

(B)

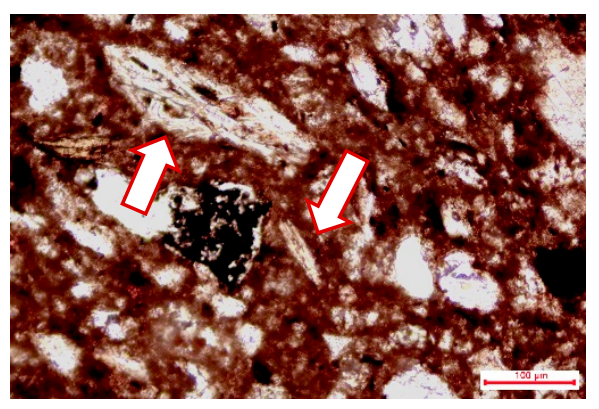

(D)

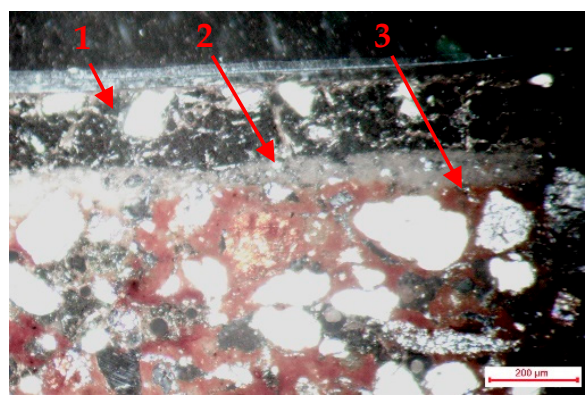

Figure 7. Photomicrographies of tile samples observed by PLM: (A) TPR9BT (xpl). Matrix appearance, aggregate composition (quartz, feldspar, biotite, old mortar) and distribution; (B) TPR13T (pplplane-polarised light), showing hornblende and fibrous variety of amphiboles; (C) TPR10T (xpl). A large piece of quartzite as an aggregate constituent; (D) TPR9AT (xpl). Stratigraphy: 1-glaze, 2-underglaze, 3-ceramic body.

Porosity varies from very low (around 20\% in sample TPR9A-9BT) to medium/low (in TPR13T) with mainly subrounded pores of different sizes not much homogeneously distributed.

The glaze layer in tile samples has a different colour and thickness, with embedded crystals; in TPR9AT-9BT samples between the glaze and the tile, an intermediate layer is visible (Figure 7D).

As also seen for bricks, in XRD results (Table 3) tile samples display similar composition with quartz as the main component and feldspar (plagioclase and k-feldspars) 
moderately abundant. Additionally, in TPR11T and TPR13T traces of micas and amphiboles have been found.

In this case, a temperature of $900-950{ }^{\circ} \mathrm{C}$ can also be argued for tile samples (clay minerals in traces only in TPR11T and TPR13T, dark colour of the clay matrix in all the samples).

SEM-EDS morphological and elemental analyses were performed to investigate the outer glaze and underglaze layer of tile samples; considering the outer glaze, it can be possible to establish similarities (lead-based Figure 8A, heterogeneous glazes with several mineral inclusions) and differences (presence of different elements like iron, copper, zinc, magnesium probably related to colouring agents as iron oxides and/or opacifiers; different homogeneity, porosity-gas bubbles, crystals amount). Mineral inclusions consist mainly of quartz and feldspars which may be associated with sand used as a raw material for the glaze manufacture; their presence and granulometry may be explained by an unrefined production and/or their use as opacifiers. In the technology of ceramic glazes, the silicate glassy phase can be mixed with other metal oxides (changing the glaze properties as viscosity and colour) which can act as a flux to lower the temperature of the glass melt and/or to colour it. Transition metal ions such as $\mathrm{Cu}^{2+}, \mathrm{Co}^{2+}$ or $3+, \mathrm{Mn}^{2+}$ or $3+$, etc. are added to colour the glaze becoming part of the glassy coating [37]. SEM-EDS analyses of the glazed tiles reveal the presence of iron in the two yellow glazes (TPR9A-9BT), while the addition of pigments composed of iron and copper (probably used in different proportions, concentrations, and baking atmospheres) in green-light blue (TPR10T, 11T, 14T) and in red-brownish glazes (TPR13T, 15T) is assumed. By comparing the elements corresponding to the colouring agents (iron and copper), the samples can be divided into three classes: the two yellow glazes (TPR9AT, 9BT) do not show the presence of copper, the light-blue sample (TPR14T) displays the highest content of $\mathrm{Cu}$ and the lowest of $\mathrm{Fe}$, while the red (TPR13T, 15T) and green (TPR10T, 11T) samples present a similar range of the two elements. In this regard, some studies also show that different concentrations of iron with respect to the silica of the glaze can result in colour transitions ranging from rusty to brown and green [38].

The non-vitreous underglaze presents in three samples (TPR9AT, 9BT, 14T) is composed of phyllosilicates (clay minerals) and the layer shows microcrystalline texture with low porosity. This layer can be classified as engobe which is a thin non-vitreous coating composed of a clay mixture and water; it is applied on the unfired object mainly to smooth the surface, correct defect and/or decorate the ceramic artefact with the addition of colouring agents [39]. The presence of lead into the engobe and in the clay body near the glaze (in samples without an intermediate layer) is probably due to the diffusion process and migration of elements during firing; indeed, during this stage, the molten glaze reacts with the clay body: chemical diffusion of $\mathrm{K}, \mathrm{Al}, \mathrm{Fe}, \mathrm{Ca}$ and $\mathrm{Si}$ from the body to the glaze and of $\mathrm{Pb}$ from glaze to the body occurs. So, the diffusion of elements into the glaze can produce an interface composed of $\mathrm{Pb}$-rich feldspars crystalline phases incorporating potassium and aluminium from the clay body (Figure 8B). This phenomenon depends on the thermal paths followed (firing time and temperature, cooling rates), the clay body composition and the procedure of glaze application (raw or fired clay body) [40]. The samples with an engobe display the lowest presence of crystallites: the glaze was probably applied on fired clay in a double-fired process (since the degree of reaction, diffusion, and interface formation is lower with fired clay than for raw bodies [40]); the other samples show more crystallites (in particular in TPR11T and TPR15T): also, in this case, a double-fired can be hypothesised but the tiles have probably undergone different thermal paths. Whereas lead glazes melt and react at temperatures between $700^{\circ}$ and $750^{\circ} \mathrm{C}$, and they are fired at a low temperature, typically $\sim 900-1050{ }^{\circ} \mathrm{C}[40,41]$, and based on these results, the glaze seems to have been produced at a temperature between $750-900{ }^{\circ} \mathrm{C}$ by different craftsmen, or with different techniques but using the same raw materials. 
(A)
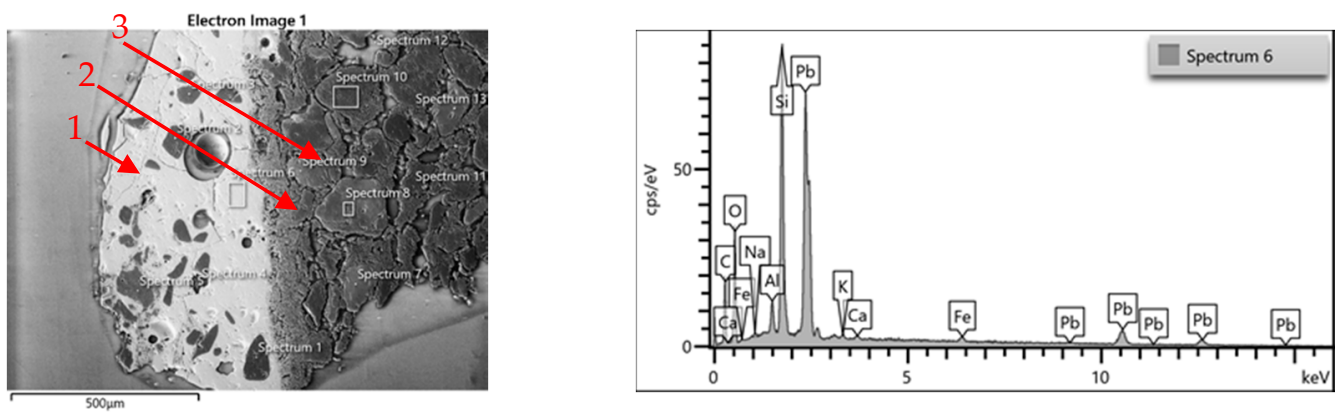

(B)
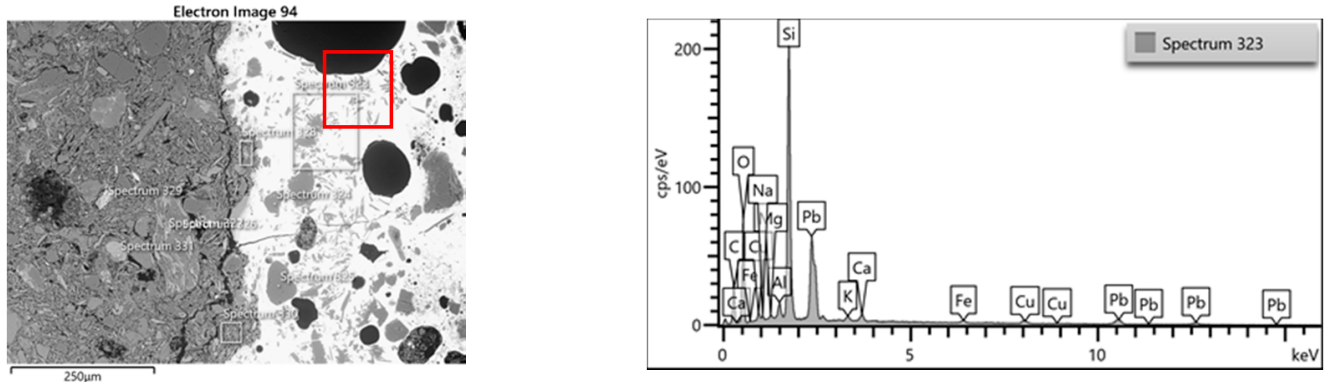

Figure 8. SEM photomicrographies with associated EDS microanalyses: (A) yellow glazed tile TPR9AT. Stratigraphy (1: glaze, 2: engobe, 3: ceramic body) with the spectrum of the glaze paste. (B) Red-brownish glazed tile TPR15T, detail of crystallite. The spectrum of the glaze paste with crystallite was obtained through EDS microanalysis.

Raman spectroscopy has been selected to obtain information on the coloured glaze components. Even though all samples of tiles (TPR9AT-TPR15T) have been analysed, significant results were obtained for sample TPR15T, here reported. By comparing standard spectra, the colouring agent probably used for the dark red glaze (TPR15T) was identified as goethite (correspondence of the intense peak at around $380 \mathrm{~cm}^{-1}$, Figure 9). Further two smaller peaks are observable in the black spectrum in Figure 9, which are probably related to small amounts of siderite/maghemite (peaks at around $745 \mathrm{~cm}^{-1}$ ) [42]. Further analyses in all other samples of tiles and elaboration of the obtained data are necessary to get a better understanding of the possible compounds present and detectable by this technique.
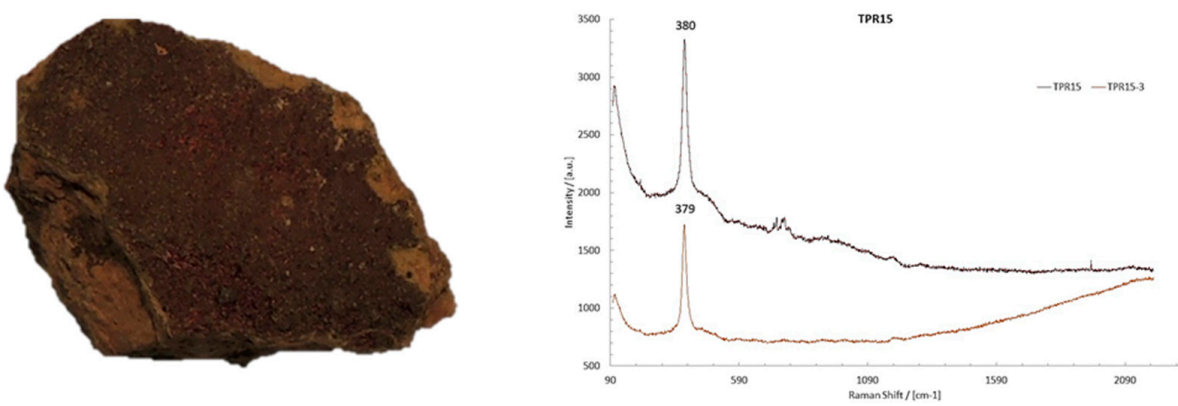

Figure 9. Comparison between two spectra (left) of red-brownish glaze TPR15T (right) detected in different points. The peaks at $379-380 \mathrm{~cm}^{-1}$ can be associated with goethite.

\subsection{State of Conservation}

Concerning the state of conservation of the ruined site under investigation, as highlighted in Section 2, it can be affirmed that it is the result of many years of abandonment and exposure to severe climate conditions (Figure 2). Anthropogenic degradation due to vandalism is also present on some walls. In particular, severe impact of graffiti, like engraving, scratching and cutting on the surface of some plastered walls (Figure 10A). 
(A)

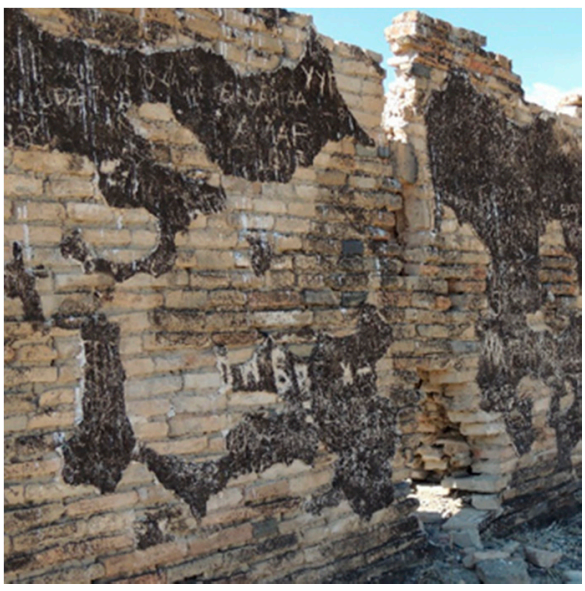

(B)

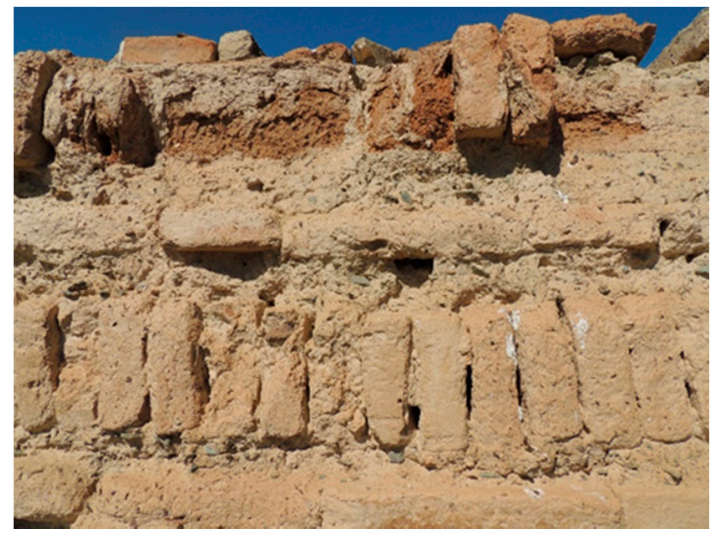

Figure 10. Photos representing portions of the remains of the wall of the archaeological site showing examples of damage on the plaster due to the presence of graffiti (engraving, scratching and cutting on the wall surface, (A) and erosion and lack of materials due to environmental impact on the building materials $(\mathbf{B})$.

Plasters and mortars present damage from moderate to severe mainly related to material loss and biological colonisation (also detected by PLM on sample TPR1P-Figure 4C). Microkarst and dissolution due to water run-off and the presence of lichens are particular observable (Table 2). Generally, bricks are characterised by a lower degree of damage (from mild to moderate) mainly due to loss of material, fracturing, erosion and biological colonisation (Table 2). Tiles samples are well preserved. As explained in Section 1.2 on the climatic setting, following Köppen-Geiger classification the site under investigation is exposed to a cool continental climate/subarctic climate (Dwc) with long, dry, very cold winters and short, warm summers. This regime is known to be dominated by mechanical processes of stone breakdown over chemical ones, mainly linked to freeze-thaw cycling, expansion shrinkage, thermoclastism and wind erosion (Figure 10B) [43].

To verify the possible impact of salts (crystallisation and solubilisation cycling), samples of plasters and mortars have been also investigated through IC analyses, as they represent the most easily degradable masonry's components. Regarding anions, the results show sulphate concentrations ranging from $0.05 \%$ to $0.25 \%$ indicating a general negligible impact, with the exception for sample TPR6M for which it can be considered mild. Chloride and nitrate concentrations, always lower than $0.04 \%$, are also considered irrelevant for the overall state of conservation (Table 5).

Table 5. Anion and cation concentrations (ppm) in plasters (TPR1P, TPR5P) and mortars (TPR2M, TPR6M) measured by IC.

\begin{tabular}{cccccccc}
\hline Sample & $\mathbf{P O}_{4}{ }^{3-}$ & $\mathbf{C}_{\mathbf{2}} \mathbf{O}_{\mathbf{4}}{ }^{-}$ & $\mathbf{N O}_{2}{ }^{-}$ & $\mathbf{N O}^{-}$ & $\mathbf{S O}_{4}{ }^{-}$ & $\mathbf{C l}^{-}$ & $\mathbf{F}^{-}$ \\
\hline TPR1P & 621 & 542 & 45 & 107 & 645 & 152 & 227 \\
\hline TPR2M & 240 & 27 & 11 & 208 & 531 & 210 & 66 \\
\hline TPR5P & 295 & 139 & 26 & 358 & 1464 & 314 & 49 \\
\hline TPR6M & 211 & 39 & 40 & 91 & 2504 & 134 & 119 \\
\hline
\end{tabular}

\section{Conclusions}

Samples of the Tsogt Palace' ruins have been collected and analysed with the aim to (a) characterise the building materials from the mineralogical and petrographic point of view; (b) identify the raw materials used and the process of production; (c) determine the state of conservation in relation to the environmental context. 
The obtained results allowed us to highlight the probable use of calcic lime as a binder in mortar and plaster samples, while the sample of material collected from the pile near the ruins resulted to be a mixture of calcic and magnesian lime, and therefore not likely used for their production.

Concerning bricks and tiles, a non-calcareous clay has been identified as raw material for their manufacture. Based on the absence of clay minerals and the amorphous appearance of the ceramic body, a firing temperature of $900-950{ }^{\circ} \mathrm{C}$ is suggested for all brick samples with exception of sample TPR3B, for which a fire temperature ranging from $850{ }^{\circ} \mathrm{C}$ and $900{ }^{\circ} \mathrm{C}$ could be suggested. Almost all samples display a high content of aggregate which is mainly composed of quartz, feldspars, similar types of metamorphic rocks fragments (quartzite), micas, and amphiboles; the abundance of detrital grains in tiles and bricks also confirms the use of non-calcareous clays.

The glazes applied to the tile samples show similar chemical composition but different applications: they are coloured lead-based glazes with a high amount of silica and embedded crystals. Colouring agents are probably pigments composed of iron and copper, used in different proportions, concentrations and firing atmospheres to obtain the different colours. Three samples display an engobe in the interface ceramic body-glaze and a higher lead rate into the coating. Considering the results, it can be supposed a double-firing process with a temperature between $750-900{ }^{\circ} \mathrm{C}$. Based on these results, the samples appear to have the same origin of production. The main differences are probably related to the use of several mixtures of raw materials and/or different thermal processes. In particular, the different methods of application of glazes can be connected to experimentation or production by different craftsmen and/or different periods of time.

Regarding the state of conservation, the site presents structural unstable conditions with the roof of the original building no longer present and most of the perimetral brick walls at risk of collapse. Original plastering mortars are almost totally absent and bedding mortars frequently eroded and decohesionated, presenting, in general, a high degree of damage mainly due to physical processes. A lower degree of deterioration has been encountered on brick samples, while tiles are well preserved. The investigations confirmed a prevailing effect of mechanical processes of damage over chemical ones, characteristic of cool continental/subarctic climate.

Ensuring the structural stability of the brick walls at risk of collapse as well as planning and adopting an efficient maintenance program for the rehabilitation works of the entire archaeological site, are therefore recommended to preserve the authenticity of the historical fabric from natural and anthropic degradation.

In conclusion, this work intends to be the basis for development in knowledge regarding the manufacturing techniques (starting from the raw materials used) and production of building materials of ancient Mongolia, bringing to light also the types of deterioration affecting masonries materials in an environment with the specific climatic context. The knowledge acquired is an important preliminary step for future rehabilitation design of the archaeological site where numerous information regarding building materials employed, structural elements features, construction techniques and the main cause of decay are needed.

Author Contributions: For this article authors contributed as follow. Conceptualization, A.B. and A.S.; methodology, A.B. and A.S.; analysis, A.S., S.C., E.M. and F.T.; investigation, A.S. and S.C.; resources, A.B.; data curation, E.M., S.C. and A.S.; writing-original draft preparation, A.S. and S.C.; writing-review and editing, A.B., A.S. and E.M.; supervision, A.B. All authors have read and agreed to the published version of the manuscript.

Funding: This research received no external funding.

Data Availability Statement: Data are contained within the Master Thesis "Canevarolo S., 2020. The Mongolian Tsogt Palace's ruins: Materials characterization and Damage assessment. Master in Science for the Conservation-Restoration of Cultural Heritage Class LM-11-Conservation and Restoration of the cultural heritage. University of Bologna". 
Acknowledgments: This study was carried out in the framework of the UNESCO/Monaco Funds-inTrust Project "Capacity-Building and Awareness-Raising for the Preservation, Conservation, Visibility and Sustainable Management of the Archaeological Site of Shoroon Bumbagar of Mount Maikhan. The authors are very grateful to Orlando Favoni from UNIVPM, and the colleagues of the National Center for Cultural Heritage of Mongolia for supporting in sampling campaign and providing bibliographical materials useful in the research related to the State of the Art.

Conflicts of Interest: The authors declare no conflict of interest.

\section{References}

1. López-Arce, P.; García-Guinea, J. Weathering traces in ancient bricks from historic buildings. Build. Environ. 2005, 40, 929-941. [CrossRef]

2. Amoroso, G.G. Trattato di Scienza della Conservazione dei Monumenti: Etica della Conservazione, Degrado dei Monumenti, Interventi conservativi, Consolidanti e Protettivi; Alinea Editrice: Florence, Italy, 2002.

3. Jin, P.J.; Zhang, Y.; Wang, S.; Yang, X.G.; Zhang, M. Characterization of the superficial weathering of bricks on the City Wall of Xi'an, China. Constr. Build. Mater. 2017, 149, 139-148. [CrossRef]

4. Comite, V.; De Buergo, M.Á.; Barca, D.; Belfiore, C.M.; Bonazza, A.; La Russa, M.F.; Pezzino, A.; Randazzo, L.; Ruffolo, S.A. Damage monitoring on carbonate stones: Field exposure tests contributing to pollution impact evaluation in two Italian sites. Constr. Build. Mater. 2017, 152, 907-922. [CrossRef]

5. Marrocchino, E.; Telloli, C.; Pedrini, M.; Vaccaro, C. Natural stones used in the Orsi-Marconi palace façade (Bologna): A petro-mineralogical characterization. Heritage 2020, 3, 1109-1123. [CrossRef]

6. Fermo, P.; Comite, V.; Ciantelli, C.; Sardella, A.; Bonazza, A. A multi-analytical approach to study the chemical composition of total suspended particulate matter (TSP) to assess the impact on urban monumental heritage in Florence. Sci. Total. Environ. 2020, 740, 140055. [CrossRef]

7. Grossi, C.M.; Brimblecombe, P. Effect of long-term changes in air pollution and climate on the decay and blackening of European stone buildings. Geol. Soc. Lond. Spec. Publ. 2007, 271, 117-130. [CrossRef]

8. Basu, S.; Orr, S.A.; Aktas, Y.D. A geological perspective on climate change and building stone deterioration in London: Implications for urban stone-built heritage research and management. Atmosphere 2020, 11, 788. [CrossRef]

9. Sardella, A.; Palazzi, E.; von Hardenberg, J.; Del Grande, C.; De Nuntiis, P.; Sabbioni, C.; Bonazza, A. Risk mapping for the sustainable protection of cultural heritage in extreme changing environments. Atmosphere 2020, 11, 700. [CrossRef]

10. Bonazza, A.; Messina, P.; Sabbioni, C.; Grossi, C.M.; Brimblecombe, P. Mapping the impact of climate change on surface recession of carbonate buildings in Europe. Sci. Total. Environ. 2009, 407, 2039-2050. [CrossRef]

11. Gómez-Bolea, A.; Llop, E.; Ariño, X.; Saiz-Jimenez, C.; Bonazza, A.; Messina, P.; Sabbioni, C. Mapping the impact of climate change on biomass accumulation on stone. J. Cult. Herit. 2012, 13, 254-258. [CrossRef]

12. Bonazza, A.; Sabbioni, C.; Messina, P.; Guaraldi, C.; De Nuntiis, P. Climate change impact: Mapping thermal stress on Carrara marble in Europe. Sci. Total. Environ. 2009, 407, 4506-4512. [CrossRef]

13. Ciantelli, C.; Palazzi, E.; Von Hardenberg, J.; Vaccaro, C.; Tittarelli, F.; Bonazza, A. How can climate change affect the UNESCO cultural heritage sites in Panama? Geosciences 2018, 8, 296. [CrossRef]

14. Tumen, D.; Navaan, D.; Erdene, M. Archaeology of the Mongolian period: A brief introduction. Silk Road 2006, 4, 51-55.

15. Habu, J.; Lape, P.V.; Olsen, J.W. Handbook of East and Southeast Asian Archaeology, 1st ed.; Springer: New York, NY, USA, 2017.

16. Solmon, Ј. Монгол нутаг дахь түүх, соёлын үл хөдлөх дурсгал Орч. Ц.Цолмон/Historical and Cultural Immovable Properties in Mongolia; Cultural Heritage Center: Ulaanbaatar, Mongolia, 2012.

17. Bemmann, J.; Reichert, S. Karakorum, the first capital of the Mongol world empire: An imperial city in a non-urban society. Asian Archaeol. 2020, 4, 121-143. [CrossRef]

18. Historical Dictionary of Mongolia-Alan J.K. Sanders-Google Libri. Available online: https://books.google.it/books?id=5JN8 3EDDL14C\&pg=PA60\&dq=tsogt+palace+ruins+mongolia+history\&hl=it\&sa=X\&ved=0ahUKEwjpzdTandPlAhXCyaQKHcX_ DMsQ6AEIMTAB\#v=onepage\&q=tsogtpalaceruinsmongoliahistory\&f=false (accessed on 14 November 2019).

19. Erdenebold, L.; Tolnai, K.; Harmath, A.; Siklodi, C.; Szilagyi, Z.; Laslovzky, J. Research on landscape archaeology in the context of nomad towns: Results of the third field season of the KHI-LAND project, 2018. Hung. Archaeol. 2018, 7, 15-25.

20. Rinchinkhorol, M. Mongolia. In The Twentieth Regular Report; Nara, 2018; Volume 13, pp. 23-25. Available online: https: / / www.google.com.hk/search?q=The+Twentieth+Regular+Report (accessed on 4 January 2020).

21. Remaining of White House of Prince Tsogt. Available online: https://mongolia-guide.com/place/remaining-of-white-house-ofprince-tsogt (accessed on 21 November 2019).

22. Chuluun, S.; Enkhtuul, C.; Battsooj, В. Archaeological Excavation Report: 'ХVII ЗУУНЫ МОНГОЛЫН ХОТУУД' ТӨСӨЛ. БУЛГАНАЙМГИЙН БАЯННУУРСУМЫН НУТАГ ДАХЬ ЦОГТЫН ЦАГААН БАЙШИНГИЙН ТУУРЬТ ЯВУУЛСАН; Ulaanbaatar, Mongolia, 2018.

23. Climate Risk Profile Mongolia. 2017. Available online: https://www.climatelinks.org/resources/climate-change-risk-profile-mongolia (accessed on 4 January 2020).

24. Otgonbayar, M.; Atzberger, C.; Mattiuzzi, M.; Erdenedalai, A. Estimation of climatologies of average monthly air temperature over mongolia using MODIS land surface temperature (LST) time series and machine learning techniques. Remote Sens. 2019, 11, 2588. [CrossRef] 
25. Doljinsuren, A.B.J.; Suzanna, S. Mongolia Voluntary National Review 2019. Implementation of the Sustainable Development Goals, Ulaanbaatar. 2019. Available online: https://sustainabledevelopment.un.org/content/documents/23342MONGOLIA_ VOLUNTARY_NATIONAL_REVIEW_REPORT_2019.pdf (accessed on 6 June 2021).

26. Vergès-Belmin, V. Illustrated Glossary on Stone Deterioration Patterns; Monuments and Sites XV; ICOMOS: Paris, France, 2008.

27. Terry, R.D.; Chilingar, G.V. Percent coverage comparison charts. J. Sediment. Petrol. 1955, 24, 229-234. [CrossRef]

28. Yaseen, I.A.B.; Al-Amoush, H.; Al-Farajat, M.; Mayyas, A. Petrography and mineralogy of Roman mortars from buildings of the ancient city of Jerash, Jordan. Constr. Build. Mater. 2013, 38, 465-471. [CrossRef]

29. Diekamp, A.; Konzett, J.; Mirwald, P.W. Magnesian lime mortars-Identification of magnesium phases in medieval mortars and plasters with imaging techniques. In Proceedings of the 12th Euroseminar on Microscopy Applied to Building Materials, Dortmund, Germany, 14-18 September 2009; pp. 309-317. Available online: https:/ / www.researchgate.net/publication/236875128 (accessed on 6 June 2021).

30. Pecchioni, E.; Fratini, F.; Cantisani, E. Atlante delle Malte Antiche in Sezione Sottile al Microscopio Ottico; Nardini Editore: Florence, Italy, 2014.

31. Montoya, C.; Lanas, J.; Arandigoyen, M.; Navarro, I.; Casado, P.G.; Alvarez, J.I. Study of ancient dolomitic mortars of the church of Santa María de Zamarce in Navarra (Spain): Comparison with simulated standards. Thermochim. Acta 2003, 398, 107-122. [CrossRef]

32. Villaseñor, I.; Price, C.A. Technology and decay of magnesian lime plasters: The sculptures of the funerary crypt of Palenque, Mexico. J. Archaeol. Sci. 2008, 35, 1030-1039. [CrossRef]

33. Ouahabi, M.E.; Daoudi, L.; Hatert, F.; Fagel, N. Modified mineral phases during clay ceramic firing. Clays Clay Miner. 2015, 63, 404-413. [CrossRef]

34. Albero Santacreu, D. Materiality, Techniques and Society in Pottery Production: The Technological Study of Archaeological Ceramics through Paste Analysis; De Gruyter Open Ltd.: Berlin, Germany, 2014.

35. López-Arce, P.; Garcia-Guinea, J.; Gracia, M.; Obis, J. Bricks in historical buildings of Toledo City: Characterisation and restoration. Mater. Charact. 2003, 50, 59-68. [CrossRef]

36. Cardiano, P.; Ioppolo, S.; De Stefano, C.; Pettignano, A.; Sergi, S.; Piraino, P. Study and characterization of the ancient bricks of monastery of "San Filippo di Fragalà" in Frazzanò (Sicily). Anal. Chim. Acta 2004, 519, 103-111. [CrossRef]

37. Tanevska, V.; Colomban, P.; Minčeva-Šukarova, B.; Grupče, O. Characterization of pottery from the Republic of Macedonia I: Raman analyses of Byzantine glazed pottery excavated from Prilep and Skopje (12th-14th century). J. Raman Spectrosc. 2009, 40, 1240-1248. [CrossRef]

38. Hoo, Q.; Wang, X.; Yuan, F.; Cao, X.; Cao, T.; Zhang, M. Microstructure and coloring mechanism of iron spots on bluish white porcelain from Jingdezhen of the Song Dynasty. J. Eur. Ceram. Soc. 2021, 41, 3816-3822. [CrossRef]

39. Ricci, G. Archaeometric Studies of Historical Ceramic Materials; Università Ca'Foscari: Venice, Italy, 2016.

40. Molera, J.; Pradell, T.; Salvadó, N.; Vendrell-Saz, M. Interactions between clay bodies and lead glazes. J. Am. Ceram. Soc. 2001, 84, 1120-1128. [CrossRef]

41. Pradell, T.; Molera, J. Ceramic technology. How to characterise ceramic glazes. Archaeol. Anthropol. Sci. 2020, 12, 1-28. [CrossRef]

42. Hanesch, M. Raman spectroscopy of iron oxides and (oxy)hydroxides at low laser power and possible applications in environmental magnetic studies. Geophys. J. Int. 2009, 177, 941-948. [CrossRef]

43. Peltier, L.C. The geographic cycle in periglacial regions as it is related to climatic geomorphology. Ann. Assoc. Am. Geogr. 1950, 40, 214-236. [CrossRef] 